\title{
Sentipensar mapuche con las aguas del Huenehue: Hacia una ecología política y una antropología por demanda
}

\author{
María Ignacia Ibarra Eliessetch \\ Universidad de Barcelona, Barcelona, España. \\ Email: ignacia.ibarra@gmail.com \\ Wladimir Riquelme Maulén \\ Centro UC Desarrollo Local, Villarrica, Chile. \\ Email: wladiriquelme@gmail.com
}

\begin{abstract}
Resumen: La biodiversidad se ha devastado considerablemente por actividades extractivistas en territorios habitados por pueblos originarios. Este artículo surge del peritaje antropológico que se "demandó” por parte de la Asociación Leufu Wueneywue y que fue realizado en Tralcapulli y Llongahue (Región de Los Ríos, Chile) debido a la instalación de la Hidroeléctrica Pullinque hace más de 50 años. A partir de una metodología participativa y un enfoque teórico basado en una ecología política mapuche, se presenta la articulación de memorias sociecológicas y prácticas políticas para la recuperación del cuerpo de agua del Huenehue. Se constata la devastación del sistema de vida vinculado al río y se caracteriza el sentipensar del territorio por medio de las representaciones, significados y vivencias que se articulan con procesos de autodeterminación política. Finalmente, se plantea la pertinencia de la recuperación del río para una ecología política que surge del diálogo de saberes populares y técnicos.
\end{abstract}

Palabras claves: Sentipensar mapuche; devastación de la vida; río Huenehue; antropología por demanda.

\section{Thinking and feeling Mapuche with the waters of Huenehue: Towards a political ecology and an anthropology on demand}

\begin{abstract}
Biodiversity has been considerably devastated by extractive activities in territories inhabited by indigenous peoples. This article arises from the anthropological survey “demanded” by the LeufuWueneywue Association and carried out in Tralcapulli and Llongahue (Los Ríos Region, Chile) due to the installation of the Pullinque Hydroelectric more than 50 years ago. From a participative methodology and a theoretical approach based on a Mapuche political ecology, the articulation of sociecological memories and political practices for the recovery of the body of water of the Huenehue is presented. The devastation of the system of life linked to the river is verified and the thinking and feeling of the territory is characterized by means of representations, meanings and experiences that are articulated with processes of political selfdetermination. Finally, the relevance of the recovery of the river for a political ecology that arises from the dialogue of popular and technical knowledge is raised.
\end{abstract}

Keywords: Thinkingand feeling mapuche; devastation of life; Huenehueriver; anthropology on demand.

\section{Sentipensar Mapuche com as águas de Huenehue: Para uma ecologia política e uma antropologia por demanda}

Resumo: A biodiversidade foi devastada consideravelmente pelas atividades extrativistas em territórios habitados por povos indígenas. Este artigo resulta da pesquisa antropológica que fue “demandada” pela Associação Leufu Wueneywue e foi realizada em Tralcapulli e Llongahue (Los Ríos Region, Chile) devido à instalação da Hidrelétrica Pullinque faz mais de 50 anos atrás. A partir de uma metodologia participativa e da teoria baseada numa abordagem da ecologia política Mapuche, apresentase a articulação de memórias sociecológicas e práticas políticas para a recuperação do corpo de água 
Huenehue. Constata-se a devastação do sistema de vida ligada ao rio e caracteriza-se o sentipensar do território através das representações, significados e experiências que se articulam com os processos de autodeterminação política. Por fim, considera-se a relevância da recuperação do rio para uma ecologia política que seja decorrente do diálogo de saberes populares e técnicos.

Palavras-chave: Sentipensar mapuche; devastação da vida; rio Huenehue; antropologia por demanda.

\section{Introducción}

Días de verano, días con extremo calor en Wallmapu ${ }^{1}$, sur de Chile. La gente habla de estas temperaturas como expresión del cambio climático y la ausencia de las aguas originarias. Estamos en la ribera sur de un río cuyas aguas se encuentran desviadas por una central hidroeléctrica. Las familias mapuche reclaman por su restitución. Mapuche, "gente de la tierra" les dicen los que traducen su nombre del mapuzungun al castellano. Gente de la tierra, también del agua, del viento, de los árboles, de la naturaleza en su conjunto y cotidianeidad. "La mapu lo es todo" nos dijo una señora -amiga-interlocutora en nuestro estudio. Tralcapulli es un lof, unidad territorial por linaje. Un espacio en donde antiguamente atravesaba un río, que oficialmente se conoce como "Huenehue”, pero que para la comunidad es Wueneywue y así le nombran todavía, "lugar de amigos”2. Ese cuerpo de agua constituía la frontera natural entre Tralcapulli y el lof vecino de Llongahue. Pero no era como las fronteras que conocemos con la carga histórica que ese concepto hoy tiene: lugares conflictivos que establecen límites territoriales inexpugnables, muros, violencia. En este caso, el río Huenehue era un espacio de encuentro entre las personas que habitaban las dos riberas, un espacio en donde se iba a buscar agua para tomar, se les daba de beber a los animales, se lavaba ropa, y donde las personas se bañaban en días de calor como aquel en donde nosotros caminábamos bajo el sol sin ya tener esa posibilidad de refrescarnos junto al río.

Ambos lof deciden demandar a la empresa privada por la restitución del caudal ecológico del río Huenehue y nos invitan a elaborar el informe antropológico. Somos testigos de un sentipensar mapuche con las aguas del Huenehue a partir de laarticulación entre memorias y prácticas locales como un diseño socioecológico (Escobar, 2016) de una ecología política mapuche contemporánea (Di Giminiani, 2018). El artículo se nutrirá de esta experiencia para analizar las posibilidades y alcances de una ecología política y antropología por demanda (Segato, 2013). Fuimos testigosde diversas prácticas de autodeterminación mapuche que constituyen una alternativa latinoamericana de la ecología política: una profunda articulación entre naturaleza e historia (Escobar, 1999) entramada en la recuperación del cuerpo de agua del Huenehue.

Aunque ya han pasado varios años desde que se instaló la Hidroeléctrica en el territorio, las familias mapuche lo resienten como si hubiese sido ayer que les secaron su río, como si hubiese sido ayer que les perforaron al cerro Pitrén, como si hubiese sido ayer que el ngen del río hubiese muerto. Por ello es que se nos solicita, se nos "demanda" que realicemos un estudio de carácter antropológico para identificar y evaluar la transformación que distintas prácticas culturales han sufrido desde la instalación del proyecto hidroeléctrico Central Pullinque, en el año 1962. Esto desde la mirada de habitantes del territorio, y que se agrupan en la Asociación Leufu Wueneywue para generar una demanda a la empresa privada e interpelar al Estado para recuperar el caudal que existía en ese lugar hace unas décadas atrás. En palabras de Rita Segato, lo que acontece es que

“nuestro antiguo 'objeto' clásico sea hoy el que nos interpele, nos diga quién somos y qué espera de nosotros, y nos demande el uso de nuestra 'caja de herramientas' para responder sus preguntas y contribuir con su proyecto histórico. Es por esta disponibilidad para con la solicitación de comunidades y pueblos que esta práctica disciplinar es también una antropología litigante, al servicio, interpelada” (Segato, 2013, p. 14).

Por ello se apela al diálogo de saberes (Leff, 2019) y a una visión amplificada e integral de la crisis ambiental planetaria que se relaciona directamente con los extractivismos de cuerpos y territorios y que-principalmente- son voces feministas (desde los feminismos decoloniales, ecofeminismos, feminismos territoriales, 
feminismo comunitario entre otros) las que hacen un llamado de atención y nos aproximan a una ecología política que reconoce los diversos factores que inciden en la construcción del sistema patriarcal, capitalista, colonialista y depredador de la naturaleza (Curiel, 2009; Ulloa, 2016; Cabnal, 2010; Bolados y Sánchez, 2017). Es desde esa perspectiva que en la ruka de Tralcapulli (espacio de reunión comunitaria) se ha generado una lucha mancomunada en donde hemos participado colaborativamente personas de diferentes disciplinas y procedencias con el objetivo de compartir conocimientos y aportar desde diferentes enfoques: cada vez se afirma con más fuerza la convicción de avanzar en las transformaciones ecológicas y sociales complementando saberes y conocimientos desde diferentes ámbitos.

\section{Hacia una ecología política y antropología por demanda}

La Asociación Leufu Weneywue, constituida por habitantes de Tralcapulli y Llongahue, nos solicitó la realización de un peritaje antropológico que sistematice información correspondiente a las afectaciones que se han generado a partir de la instalación y desarrollo de la Central Hidroeléctrica Pullinque en la ribera del río Huenehue. Este informe se enmarca dentro de un proceso de investigación que la misma asociación está desarrollando de manera autónoma y con la ayuda de distintos profesionales de las áreas que corresponden. Es así como la realización del trabajo antropológico se realiza en paralelo a la construcción de informes en los ámbitos jurídico y ambiental. En este sentido, si bien las disciplinas trabajan de manera independiente, toda la información recopilada va en función del mismo objetivo que se ha propuesto la Asociación; la caracterización del territorio de la ribera del río Huenehue para la formulación de propuestas y líneas de acción que puedan abordar problemáticas específicas que surjan en el devenir de las comunidades y los territorios, desde una perspectiva mapuche.

Figura 1

Ubicación del río Huenehue y principal afectación.

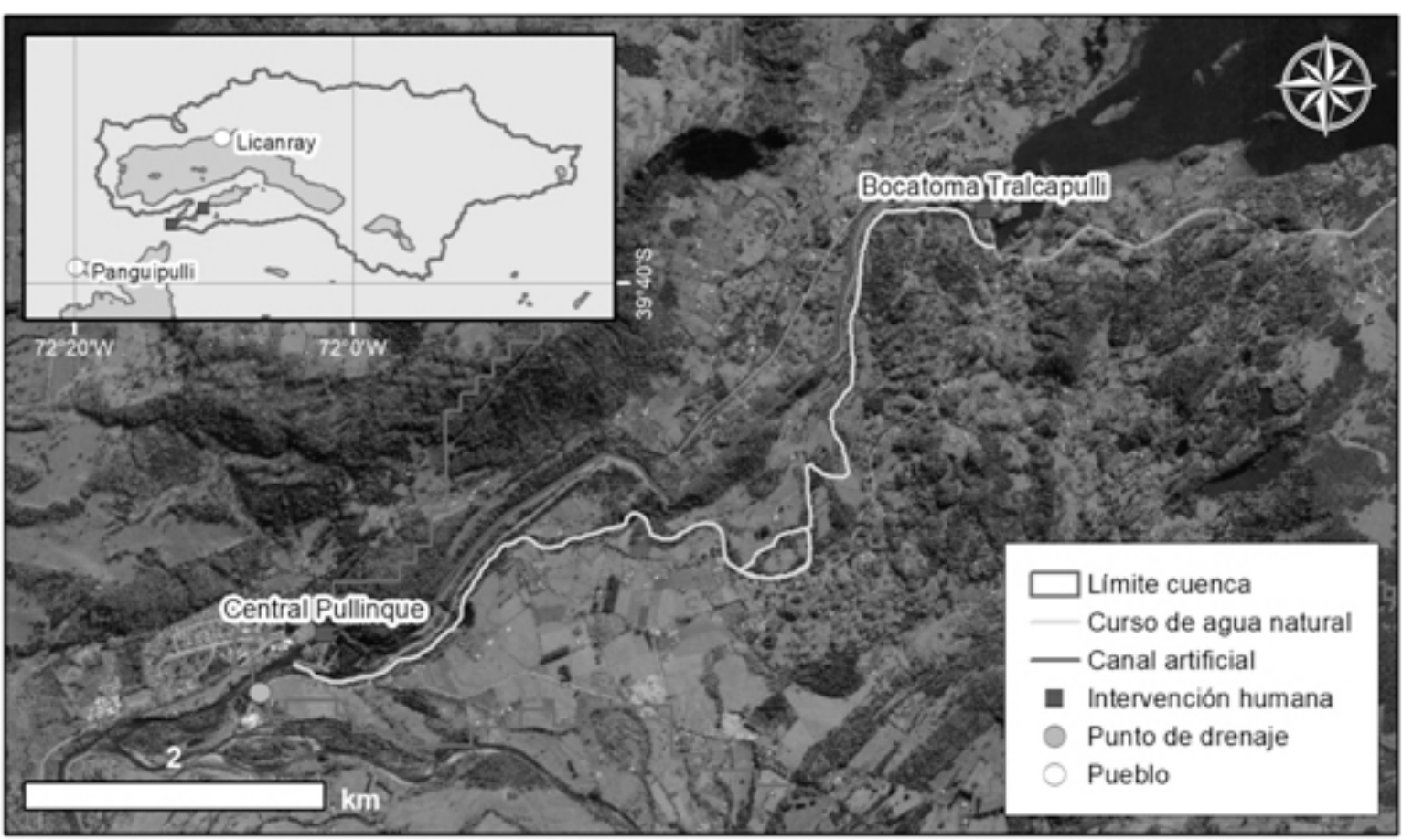

Fuente: Mapa realizado por Camila Bañales (cbanale@uc.cl). 
Como se representa en la figura 1, las aguas del Huenehue son parte de la cuenca del lago Calafquén y surgen de los deshielos en el cráter del volcán Villarrica. A través de sus quebradas, en particular la de Challupen,fluye el agua hacia el lago Calafquén. Por el río Huininca se conecta con el lago Pullinque. Esta era una antigua laguna, la cual se amplió para contener el agua y desviarla por el canal de la central hidroeléctrica. En la desembocadura del Pullinque toma el nombre de Huenehue, conectándose posteriormente con el lago Panguipulli.Desde principios del siglo XX, Chile instauró un Programa Nacional para desarrollar un sistema de energía hidroeléctrica a lo largo del territorio (Nelson, 2013). La Empresa Nacional de Energía (ENDESA) concibió la construcción de la Central Hidroeléctrica Pullinque en 1951, como parte de la quinta área geográfica del programa. Con un préstamo del Banco Interamericano, la construcción comenzó en 1954 y ocho años más tarde estaba en pleno funcionamiento. El proyecto, ubicado a dos kilómetros de su fuente, aprovecha la topografía acuífera para capturar el agua de la laguna Pullinque, produciendo 40000 kW (ENDESA, 1962). No se manifestó sobre las repercusiones que generaba en las comunidades indígenas vecinas. En la memoria local está el recuerdo de las tronaduras desde inicios de 1910 y la aparición de nuevos vecinos en el poblado de Pullinque. En la figura 2 se contrastan la ilustración realizada por la empresa de la ubicación de los canales y una imagen satelital donde los cuadrantes grises son Títulos de Merced.

Figura 2

Contraste de percepción del entorno del río Huenehue
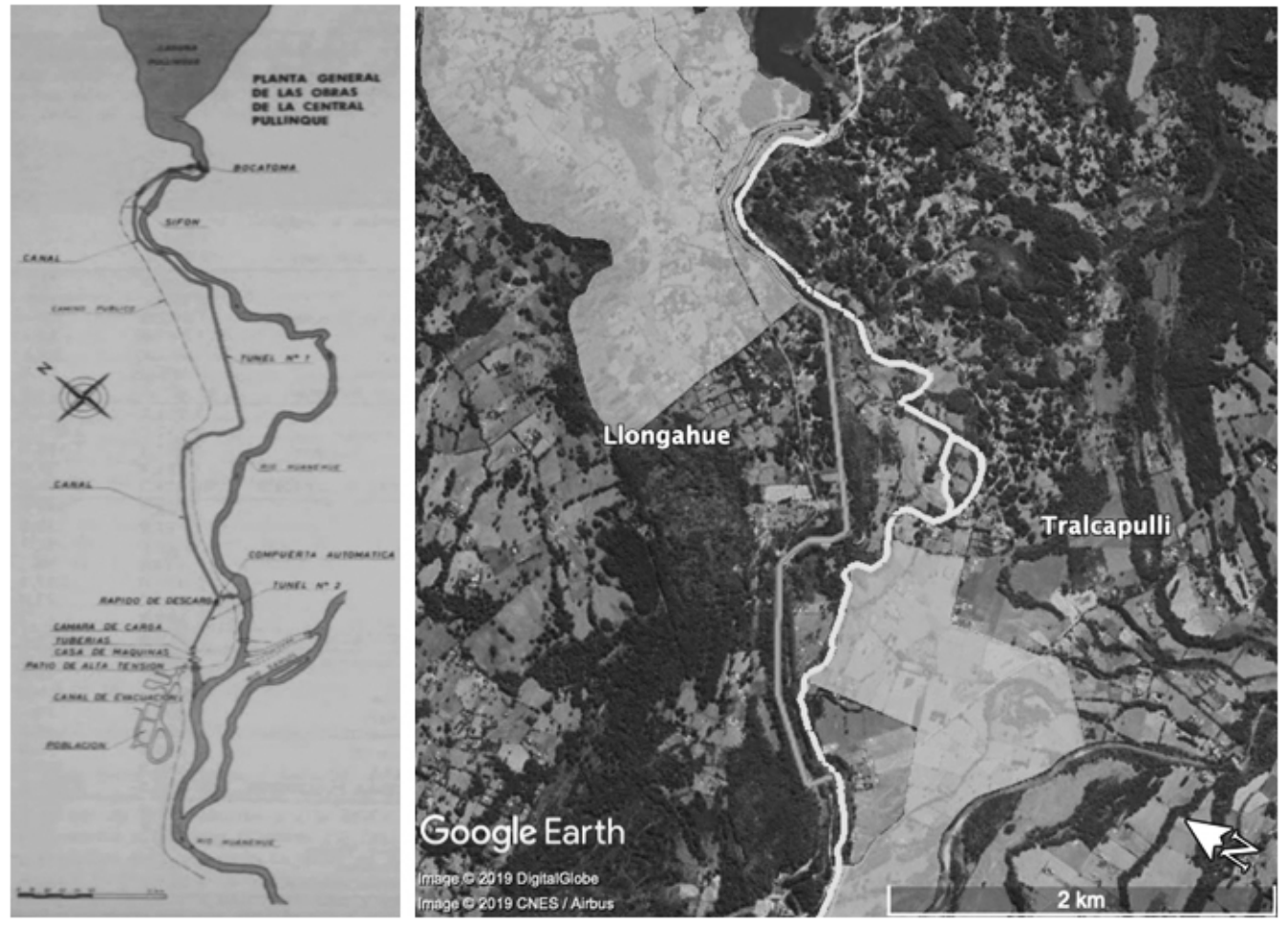

Fuente: ENDESA (1962) y elaboración propia a partir de Google Earth y SIT CONADI (2019)

Los proyectos hidroeléctricos son los causantes de los principales conflictos en el territorio mapuche actual (Yáñez y Molina, 2011). La vegetación que circunda a la línea más clara es constancia física del afluente histórico del Huenehue. A pesar de la intervención radical que significó la construcción, en su momento hubo nula protesta. El clima político del período y la casi completa negación de las poblaciones originarias del país, junto con los servicios proporcionados por ENDESA en el terremoto posterior a 1960 para la contención del amenazante aumento del río Riñihue, además de una población indígena que pudo acceder escasamente a educación formal (por lo cual era mayoritariamente analfabeta), proporcionaron un pase gratui- 
to para la operación de la planta hasta el año 2000 (año en que la transnacional Enel-Green Power compró la empresa estatal).

Una interlocutora de Tralcapulliplanteó en un nütram: “Antiguamente aquí la gente no sabía ni leer, había mucha ignorancia con respecto a las posibles formas de organización comunitaria para lograr una demanda legal”. Los procesos históricos se articulan con dinámicas de la biodiversidad (Escobar, 1999) yconstituyen una crisis socio-ecológica interpelada desde los procesos sociales. La ecología política ha sido espacio fructífero para ello, lo que ha sido analizado principalmente desde perspectivas de desarrollo (Lipietz, 2002) y actualmente desde ecologías políticas relacionales (Escobar, 2016; 2014). La perspectivadecolonial nos entrega un marco conceptual pertinente para pensar estos procesos en contexto indígenas como una "plataforma política para la construcción de alternativas al desarrollo” (Gudynas y Acosta, 2011, p. 73).

Las organizaciones comunitarias aunadas por la demanda del Huenehue son manifestación de ello.Se constituye una ecología política mapuche orientada en procesos creativos de demandas territoriales.La restitución del caudal ecológico es un diseño socioecológico (Escobar, 2016) de ambientes para la vida del futuro (Ingold, 2012), territorialmente situado y que se manifiesta en las prácticas cotidianas de las personas de Llongahue y Tralcapulli. La demanda y las prácticas cotidianas sostienen la ecología política mapuche que emerge de las aguas del Huenehue.

Lo que representa un problema técnico para Enel-Green Power constituye una amenaza cotidiana y cosmológica para los habitantes. Como lo sugirió una interlocutora, "el significado del río se deriva de su leufu ngen (custodio espiritual del río), es la conexión espiritual con los que habitan aquí”. Esto es explicado del modo que,

"la tierra por sí misma no podría producir nada, no serían árboles, ni jardines, ni animales, ni pájaros, ni reptiles: es el agua lo que engendra en la Tierra, $y$, en las alturas de las montañas, el winkul, donde cohabitan los nuevos habitantes” (Ñanculef, 2016, p. 25).

El sentipensar mapuche con las aguas del Huenehue responde a este propósito. En palabras de Arturo Escobar, "sentipensar con el territorio implica pensar desde el corazón y desde la mente, o co-razonar" (Escobar, 2014, p. 16). Es en las prácticas cotidianas donde se manifiesta el sentipensar mapuche, constituyéndose en una ecología política mapuche orientada hacia las transiciones de sustentabilidad social y ecológica (Toledo, 2019).

La integración social y ecológica del Huenehue sostiene la médula del argumento expuesto. La integraciónpermite atribuir a la memoria dimensiones ambientales a los recuerdos. Es socioecológica al localizarseen la memoria de espacios geográficos, sociales y ecológicos (Radding y Western, 2010; Nykvist, 2012) y se vincula estrechamente con los paisajes en términos de su producción(Skewes, Guerra, Rojas y Mellado, 2011). La producción de un paisaje se reconoce en un sitio al orientarse, marcar, nombrar e institucionalizar el lugar (Lindón y Hiernaux, 2006). Enunciar Weneywue a Huenehue es parte de esta producción de un paisaje políticamente mapuche. Al nombrar un lugar del paisaje se alude indirectamente "a las asociaciones de la gente con dicho lugar" (Ibid, p. 232) los cuales "se impregnan de cultura y poder" (Claval, 1995, p. 166). El carácter socioecológico de la memoria otorga un "atributo biocultural del lugar nombrado" (Rozzi y Schüttler, 2015, p. 34) e historicidad a la naturaleza en términos de regímenes de producción (Escobar, 1999).

Un modo de llevar a la práctica la perspectiva decolonial es escribir Wueneywue por Huenehue. Nombrar los lugares ha sido la forma de generar conciencia sobre la extensión del territorio ancestral mapuche (Durán y Catriquir, 2007). Como plantea Piergiorgio Di Giminiani, "los rasgos geográficos asociados al pasado se vuelven importantes para los habitantes actuales a través de las prácticas que refuerzan los vínculos con lo ancestral” (Di Giminani, 2012, p. 249-250) y, según el propio autor, se representan en el paisaje y memoria de las tierras ancestrales. En el entendimiento de Tralcapulli como "trueno del diablo" (de Moesbach, 1952) se está cometiendo un grave error. Se nos "demanda" entender los territorios desde el habitar local, desde la etimología de los nombres contextualizados en una ecología política contemporánea. Uno de los interlocutores 
nos señala que Tralcapulli hace alusión al sonido de las aguas subterráneas que resuenan en momentos de lluvia y truenos. El lente de la ecología política mapuche se sitúa en estos entendimientos locales del territorio.

\section{Metodología: la dimensión socioespacial y decolonial del peritaje antropológico}

Los datos expuestos en el artículo se nutren del peritaje antropológico que tuvo por objeto establecer el daño cultural que ha provocado la instalación de la Central Hidroeléctrica Pullinque en el río Huenehue. Un peritaje antropológico es una investigación aplicada (Berho, Castro y Le Bonniec, 2016) orientada a la generación de información por demanda (Segato, 2013) de comunidades. Sirve para acreditar prácticas y conocimiento arraigados social y territorialmente en contexto en que se ven afectados. En nuestro caso, se caracterizaron evidencias que dan cuenta de la relevancia socialespacial de la historia, cultura y espiritualidad arraigada en el río Huenehue como una parte fundamental del itrofillmogen (biodiversidad natural y cultural). Se estableció una estrategia metodológica con enfoque cualitativo ya que "se mueve en el orden de los significados y sus reglas de significación: los códigos y los documentos” (Canales, 2006, p. 19). Esto permitió registrar información correspondiente a los efectos socio-culturales que se caracterizaron.

Esta investigación también tiene una marcada perspectiva decolonial. Aníbal Quijano (2000) propone la categoría de análisis de la colonialidad (la del poder, la del saber y la del ser), como formas de poder epistemológicas y ontológicas respectivamente, que ponen el conocimiento eurocéntrico o hegemónico por sobre el de las poblaciones locales y nativas de los territorios. Para este autor, la colonialidad del poder es un principio y estrategia de dominación y control, es el hilo conductor que une la colonialidad moderna del siglo XVI con su versión actual.

La perspectiva decolonial comienza a detenerse en aquella parte de la sociedad silenciada por la academia occidental, aquella que no consigue visibilizarse, ni encuentra su espacio porque está subalternizada. Este tipo de enfoque señala la colusión histórica entre las ciencias sociales y los poderes coloniales en cuanto productores de conocimiento y representaciones que contribuyen a desarrollar la lógica de la colonialidad (Leyva y Speed, 2008, p. 35). La relevancia de la perspectiva decolonial como enfoque crítico y lugar de enunciación es la de relevar el análisis situado y de visualizar las diferencias estructurales naturalizadas que marcan a los investigadores como sujetos de observación. La antropología por demanda no es nueva, sino que ha habido un amplio sector de las ciencias sociales que, desde diferentes perspectivas teóricas, desde hace tiempo atrás ha buscado generar metodologías críticas al modelo actual (Rappaport 2007, Rodríguez 2010, Colectivo de Situaciones 2003, entre otros) lo que da cuenta de esfuerzos epistemológicos y metodológicos de dar voz al habla subalterna, aun siendo esta temática bastante polémica que para algunos sigue siendo no resuelta (Said 2010, Spivak 2011).

Para el desarrollo del peritaje antropológico, se realizó un trabajo de campo etnográfico entre los meses de enero y abril del año 2019. Este trabajo fue reflexivo (Geertz, 2003; Guber, 2013) ya que se trata de una investigación en territorio indígena -y según los criterios establecidos en el Convenio 169 de la Organización Internacional del Trabajo (OIT)- se ha considerado pertinente que la producción y el tratamiento de la información se realizara de manera participativa y colectiva. Esto quiere decir que en el desarrollo tuvo en consideración la co-construcción de los relatos y la colectivización de los resultados. Esto nos lleva a asumir una perspectiva en la cual se esté en constante diálogo con los saberes mapuche de los territorios de Tralcapulli y Llongahue. Se participó en el cotidiano de las familias mapuche, con quienes se establecieron entrevistas en profundidad de tipo nütram. Este es un espacio de encuentro y conversación en donde se transmite oralmente el mapun kimün (conocimiento) y que ha servido para mantener y fortalecer los relatos, las narraciones y lo transmitido de una generación a otra (Catriquir y Llanquinao, 2017).

La dimensión socioespacial del peritaje antropológico estuvo en la articulación de datos etnográficos, georreferencias de lugares significativos y fotografías de los lugares. Estas unidades de registro constituyeron el corpus del peritaje y son presentados en los resultados del presente artículo. Por una parte, (i) se constata la devastación del sistema de vida mapuche vinculado al río. Posteriormente (ii) se caracteriza el sentipensar del territorio por medio de las representaciones, significados y vivencias en el río. Finalmente(iii) se analiza el 
proyecto de naturaleza y recuperación del río Huenehue y su articulación con los procesos de autodeterminación política. En la figura 3 se sintetizan los cuatro elementos que se integran y constituyen el sentipensar mapuche con las aguas.

Figura 3

Esquema del sentipensar con las aguas del Huenehue

\begin{tabular}{|l|l|}
\hline $\begin{array}{c}\text { i. Devastación de la vida } \\
\text { Sentipensar mapuche } \\
\text { con las aguas } \\
\text { agua }\end{array}$ \\
\hline iii. Proyecto de territorio & iv. Autodeterminación política \\
\hline
\end{tabular}

Fuente:Elaboración propia.

\section{La devastación del sistema de vida del Huenehue}

El caudal ecológico del río Huenehue se ha visto perturbado por la instalación y desarrollo de la Central Hidroléctrica Pullinque. En la figura 4 se visualizan las principales afectaciones en el río.

Figura 4

\section{Principales afectaciones}

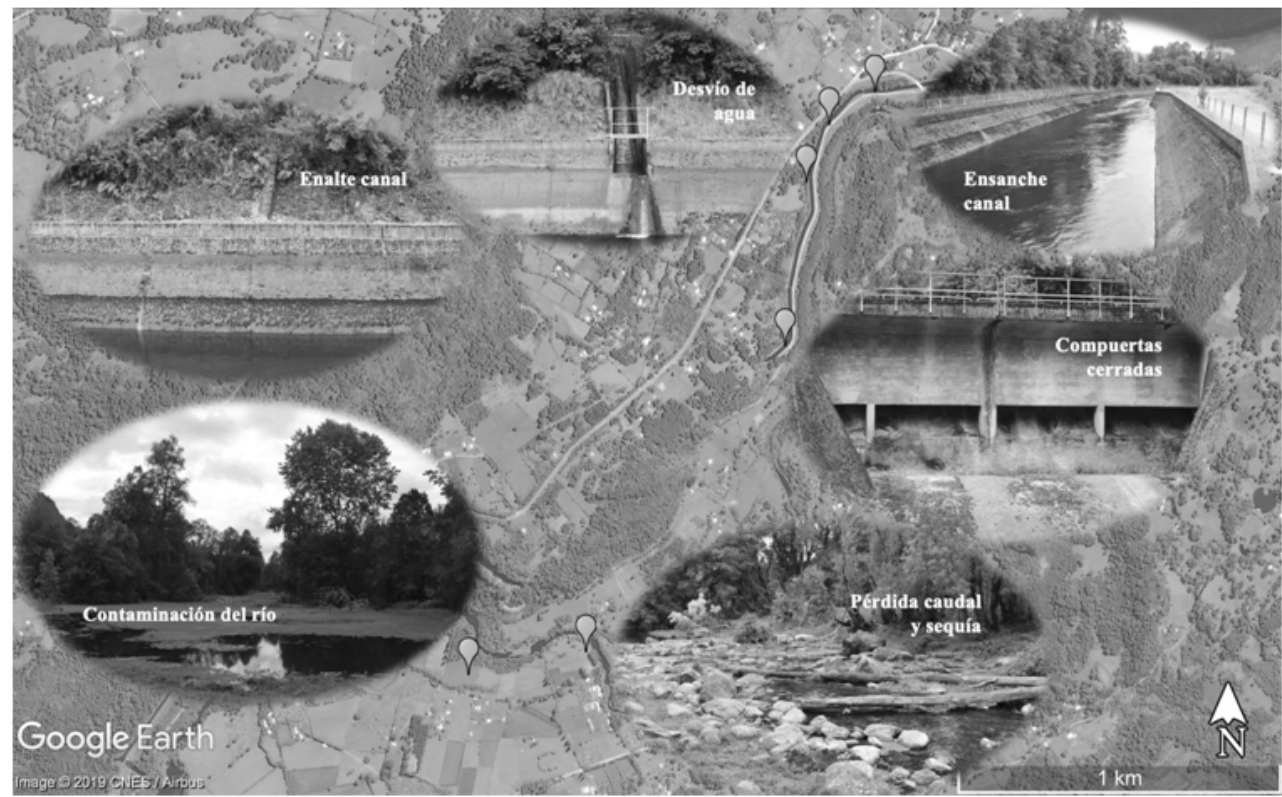

Fuente: Elaboración propia. 
La perturbación en la geografía física del territorio se ha transferido a profundos cambios en los sistemas de vida que la cultura mapuche ha vinculado al río Huenehue. El enalte y ensanche del canal, como también el desvío de agua de esteros y vertientes son cambios de infraestructura en el canal que se han realizado en beneficio de la Central y en desmedro de la población de Tralcapulli y Llongahue. Las voces locales señalan que ellas y, principalmente el cierre de las compuertas, son las principales causas de la desaparición del caudal ecológico del río. Ello se grafica en la nata rojiza producto de la contaminación del río. Las imágenes grafican los principales cambios del cuerpo de agua del Huenehue, sintetizándose en las representaciones y significados del caudal ecológico, las vivencias en el río y su importancia espiritual.

El daño cultural se refleja en el deterioro de los sitios espirituales del Truf Truf y Kuseweke.

Figura 5

Truf-Truf y Kuseweke. Sitios patrimoniales afectados
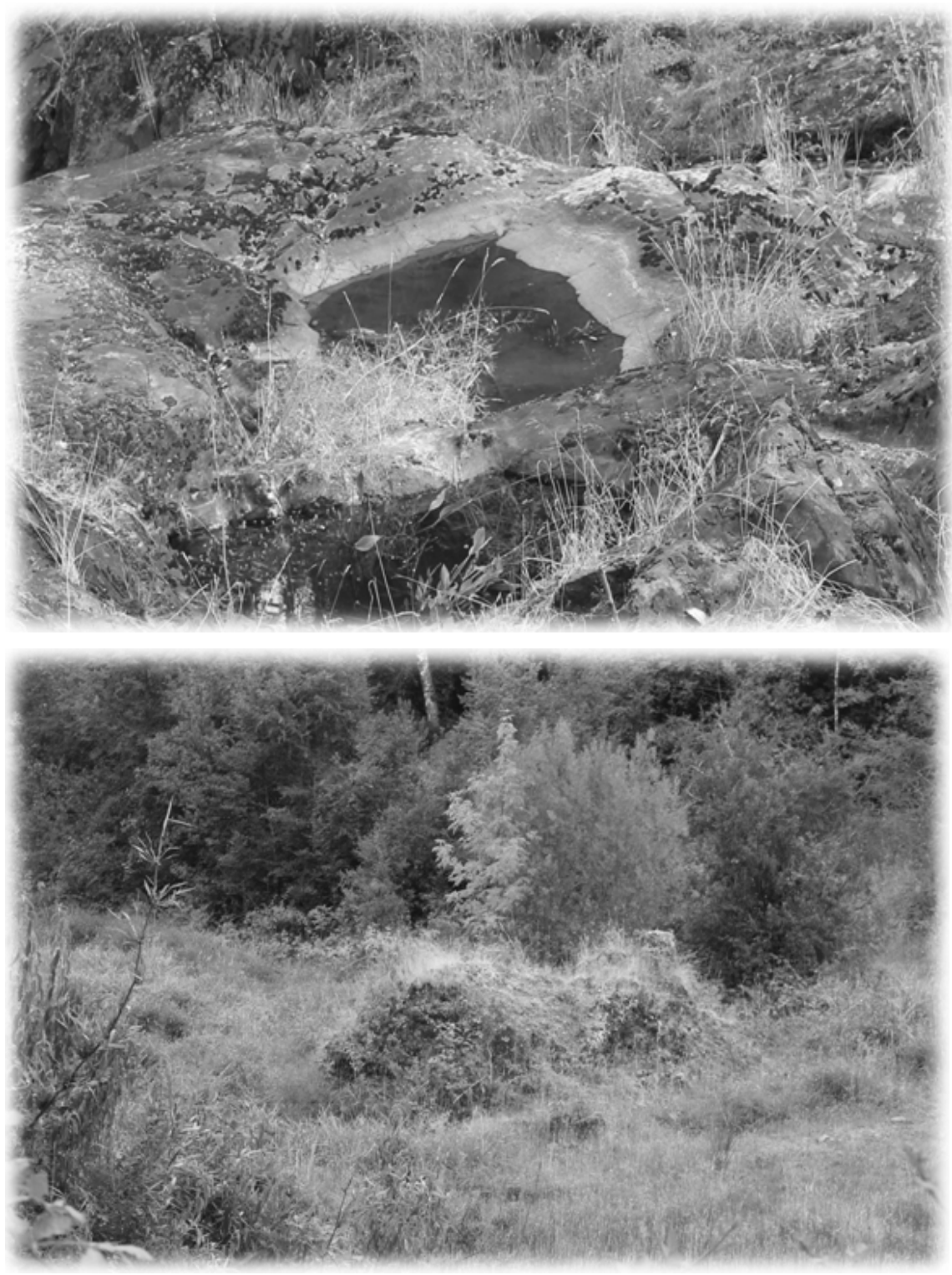

Fuente: Elaboración propia 
Ambos son espacios claves para las vivencias y espiritualidad mapuche. Truf-Truf es un espacio rocoso donde se posaba una niebla espesa producto de las aguas calientes del lugar. Se encuentra al suroeste de la zona afectada. Según uno de los interlocutores,

“es una parte donde suena el agua. Es una parte bien ancha donde pasaba el agua, y ahí pasaba el agua y sonaba. Y ahí se levantaba neblina hacia arriba con toda la fuerza que se generaba ahí... Ahora está todo eso seco”.

Otro interlocutor recuerda que "al truf truf era la parte donde más venían de otras comunidades y llevaban su alimento, nos daba qué comer”. La niebla que se posaba sobre este roquerío de aguas calientes teníagran relevancia en los ciclos agrícolas. Un interlocutor señala:

"Fue un regulador ambiental. Antes no caían heladas producto del mismo río. Eso mismo servía para las comunidades de Llongahue, Tralcapulli, Pitrén y Cayumapu. Todo eso ya no está producto de la desaparición del río Huenehue. Era un espacio de vapor amplio por donde saltaba el agua, ese vapor se expandía. Eso aumentaba en los espacios de la tarde y de la mañana. Que hoy no esté este sitio afecta a la producción y la alimentación que se deteriora producto de las heladas”.

En el desagüe del lago Pullinque, en el sector noreste del área afectada, se encuentra el Kuseweke. Es un puente rocoso que unía los sectores de Llongahue y Tralcapulli. Tuvo un rol histórico durante la ocupación hispana en el territorio. El sargento del nguillatun, un rol ancestral clave del Lof, señala que:

“Tiene relación con el cerro Pitrén, donde está el Fortín. Lo escuché muchísimo a mi abuela más que nada cuando le contaba eso a mi madre de cómo se defendieron los antiguos en la llegada de los españoles, cómo sirvió de auxilio el Kuseweke. Este es un centro ceremonial con espíritus de guerra. Los abuelos hacían nguillatun acá, porque los españoles estaban sentados arriba en el Fortín, y de allá ellos veían como los peñi acá se habían empoderado de caballos. Seguramente, al pasar los españoles se le quedaron caballos, o en la misma guerra, y ellos hicieron uso de los caballos acá en Tralcapulli. Entonces acá corrían a caballo pero eso era con una tremenda ceremonia. Con todo ese trabajo el mapuche tenía ese poder espiritual y hacía aparecer un puente ahí en el Kuseweke. Entonces los españoles, que no lo conocían, bajaron desde el Fortín (pampa de Carahue) hasta acá, cuando vieron que los mapuche hacían los mismo. Primero, como vieron que los mapuche bajaban a caballo, los españoles quisieron hacer lo mismo, y dicen que en ese cerro cayeron muchos jinetes, los caballos y la espiritualidad. Los jinetes perdieron el control de sus caballos y cayeron a la quebrada arriba. Visto aquello los españoles, indignados, vinieron buscando camino, seguramente a cruzar el río, porque seguramente se dieron cuenta de que había un dominio espiritual de los indígenas. Ahí se vinieron a encontrar con el puente. Los mapuche pasaban por su puente de ellos. Los españoles venían furiosos detrás de su enemigo y cuando venían a medio puente, el puente se cortó. Esto era una cosa espiritual. Hoy cualquiera podría decir que esto es una cosa de brujos. Pero era el poder espiritual que antes el mapuche tenía”.

Actualmente el Kuseweke es una piedra en el centro del desagüe del Lago Pullinque. Se visualiza ya que se encuentra seco. El mismo interlocutor reflexiona a través del mito del Kuseweke en su relación actual con la Central y la actualidad espiritual del pueblo mapuche del sector. Señala,

“cómo poder volver a aquellos años en que nuestros antiguos tenían ese poder espiritual, y no se requeriría de una bomba para ir a ponerla a la empresa de la Enel. Mucho nguillatun, mucha fuerza y eso volaría. Pero hoy día no tenemos esa capacidad de concentración”.

Itrofillmogen es explicado por Elicura Chihuailaf (1999) como una referencia al mundo viviente, biodiversidad y biosfera, sin limitarse a consideraciones del orden natural. La afectación del caudal ecológico del río no es solamente un daño físico al cuerpo de agua, sino que también a la vida generada en torno a él. El río Huenehue es un lugar de vida fundado en el itrofillmogen que se ve mermado por el deterioro del caudal ecológico. Uno de los interlocutores señala que: 
"El río era un espacio de resguardo del itrofilmongen, de la biodiversidad. Era un espacio de resguardo de la fauna. Antes decían que iban a buscar huevos de patos silvestres. En el río corría tanta agua que no se podía cruzar mucho. Era importante por la vivencia de ciertas especies. Cuando el río desaparece, comienza a irse más abajo. En Tralcapulli no existe prácticamente una vertiente que no esté contaminada".

El deterioro del itrofillmogen se representa en la afectación alimenticia y sus derivados (Barreau, Ibarra, Wyndham, Kozak, 2019), lo que el mismo interlocutor nos dice que se representa en:

"La pérdida del berro como comida, ensalada y medicamento. Ya no hay choritos de agua dulce. Los pescados que sacaban del río eran fuente de alimento. Era como para vivir lo que se sacaba del río, no tanto como para sacar e ir a vender, o lo que vendía era lo mínimo para comprar la sal o azúcar, pero en realidad era más para su consumo. O sea, siempre la gente mapuche ha sido muy sabia, quizás no del conocimiento del estudio, pero su sabiduría ha sido siempre de no destruir el medio ambiente, siempre ha habido la sabiduría de que el mundo no sea destruido”.

Por último, el itrofillmogen sostiene el sistema de vida del río Huenehue, personas incluidas. Una interlocutora señala que,

"Cuando murió el río empezaron los problemas, ya no hubo humedad para la siembra, ahora ya no se puede sembrar porotos porque se hiela. En cambio, antes mi mamá cosechaba harto poroto, cosechaba porotos, cosechaba maíz, porque la misma humedad que daba el río protegía a las siembras... pero el río no está normal pues. Ahora el río pasa por la canal, pero ¿̇a quién protege?, a nadie pues”.

Tanto la intervención en la infraestructura del espacio geográfico, como el deterioro de lugares significativos son síntomas de la devastación del sistema de vida del río Huenehue. El río se percibe vivo, pero cuya muerte se traduce en diversas manifestaciones sistemáticas del lugar. Las prácticas humanas se encuentran orientadas en su conjunto a la vuelta del cuerpo de agua, a su regeneración.

\section{Regeneracióndel cuerpo de agua}

El río Huenehuees donde el curso hídrico fluía antes de instalarse la Central Hidroeléctrica, y que en su etimología alude al "lugar de encuentro entre amigos", dando cuenta de una cercanía profunda con este cuerpo de agua. La ausencia del río incide en la manera en que los habitantes del territorio se desenvuelven, porque la vida mapuche está en relación permanente con la naturaleza; tanto los nütram, como literatura antropológica y etnográfica reciente (Riquelme, 2019; Di Giminiani y González, 2018; Ñanculef, 2016) dan cuenta que todas las dimensiones posibles son gracias a la tierra, que "la mapu lo es todo". Esto da cuenta de la relevancia, la centralidad de la presencia del río para que exista la biodiversidad, porque en la cadena de la vida cada elemento está conectado y tiene un sentido en el mundo. Es una construcción comunitaria de la sustentabilidad que llama a repensar la vida, a reconocer las modificaciones irreversibles en los territorios y transformaciones y reconfiguraciones culturales e identitarias, asociadas a los nuevos procesos y dinámicas económicas, que afectan las concepciones de diversos pueblos originarios y campesinos (Ulloa, 2016, p. 11).

Los testimonios manifiestan que en el pasado existía una práctica cotidiana en la cual el río era el paisaje habitual, no solo como un paisaje estético, sino también como un espacio comunitario y que proveía agua para beber (a las personas y a los animales), alimentos para comer y lawen para tratar muchos tipos de enfermedades. Una interlocutora recuerda que "mi niñez fue muy linda porque el río nos daba qué comer, nos daba de todo". Otros interlocutores señalan que

“todos los que habitábamos a la orilla del río nos bañábamos, eso era el sustento de uno: una iba a bañarse, se lavaba su ropa, le dábamos a los animales, hasta una misma se abastecía de agua. Esa era el agua que tomábamos nosotros. Porque en esos años el agua corría con su agua limpia, no estaba contaminada. Pero después hicieron la canal y pasó toda el agua por la canal. El río... ya murió el río”. 
“Muchos venían a pescar al río, llevaban su comida, sus salmones”. El río como espacio comunitario también es relevado y nombrado a la hora de encontrarse como familias, amistades y lof vecinos: "cuando aún no hacían los enaltes de la represa, llegaba mucha gente en el verano. Siempre fue un espacio de encuentro de ambas comunidades (Tralcapulli y Llongahue)”.

En las conversaciones que se tuvieron a lo largo de la etnografía se nombraron diversas especies de animales que antiguamente se encontraban en el río: ranas, pancoras, choros dulces, truchas, entre otras especies nativas.La lawentuchefe de Llongahue, mujer encargada de sanar y restituir la salud a las personas de las comunidades vecinas, se refiere enfáticamente a la enorme pérdida que significa el desvío del caudal del río Huenehue, principalmente por el daño a la flora que existía en torno:

"Pérdida de lawenes: chefecono, pata chalota, trihue (laurel), foye (canelo), poleo, menta, pila- pila, ¡todo salía tan lindo! Teníamos cerca los lawenes, en el mismo río, ahora nos pegamos tremendos piques. Me dicen que plante, pero no, hay lawenes que se van a buscar en la mañana, en la madrugada, y antes era tenerlo aquí mismo, ahora de madrugada hay que pararse e ir a buscar lejos. Las yerbas requieren agua todo el tiempo y eso no es fácil de dar, sólo se dan con un río al lado. El agua lava todas las hierbas, el río venía limpio, y ahora está todo contaminado”.

El daño ambiental provoca una repercusión cultural en el momento en que la medicina se extingue: el lawen se compone, básicamente, de yerbas silvestres que se recolectaban en la ribera de los cursos de agua. Así lo menciona una de las interlocutoras:

"Yo lo recuerdo como que estuviera corriendo no más, había mucha agua. Había bastantes remedios, pero ahora hay puros matorrales; ocupábamos la hojita de hualle, salía donde hacía remolino el río; la limpia plata también salía bastante, que se hierve para los riñones para los pulmones, servía bastante”. La vida del río, el río es una vida: los pajaritos, los peces. Yo me sentiría alegre que nos dieran un poquito de agua al menos, para que ese río volviera a vivir, porque el río ahora está muerto”.

Las personas que habitan el territorio de Tralcapulli y Llongahue hablan del río como un ente que posee una vida, un espíritu viviente, lo que en la cosmovisión mapuche se denomina como ngen. El subsistema de los ngen se identifica con:

"Espíritus dueños de la naturaleza silvestre, los cuales circunscriben su actividad al estrato cósmico terrestre: el mapu, tierra habitada por los mapuche. En los ngen residen las potencias de la naturaleza silvestre, asociadas a la caza- recolección, a sus plantas y animales que pueblan su mundo indómito" (Grebe, 1993, p. 47).

Existe una relación con aquel espíritu que protege, que acompaña y resguarda la perpetuidad de la existencia. Al momento en que al ngen se le priva de su espacio en donde se desenvolvía, las personas ribereñas creen que este desaparece, muere o, en voz de las autoridades ancestrales, dicen que está "dormido" en las profundidades del caudal del río. El ngen que es dueño de este cuerpo de agua es el que proveía de los elementos que allí había, y de acuerdo con la cosmovisión mapuche y su relación con la naturaleza, existía un respeto hacia el consumo de estos según recuerda uno de los interlocutores:

"Los pescados que sacaban del río era fuente de alimento. Era como para vivir lo que se sacaba del río, no tanto como para sacar e ir a vender, o lo que se vendía era lo mínimo para comprar la sal o azúcar, pero en realidad era más para su consumo. O sea, siempre la gente mapuche ha sido muy sabia, quizás no del conocimiento del estudio, pero su sabiduría ha sido siempre de no destruir el medioambiente, siempre ha habido la sabiduría de que el mundo no sea destruido”.

Los cambios en el caudal ecológico del río se grafican en el contraste de las siguientes fotografías. La primera es registrada por Luis Ladrón de Guevara en el año 1962 y la segunda fue registrada a principios del 2019 por el equipo. El afluente del agua se reduce al extremo en el contraste, logrando un golpe de imagen que permite cualificar el deterioro acuífero del río. 
Figura 6

Contraste de fotografías en desagüe de lago Pullinque y río Huenehue entre los años 1962 y 2019
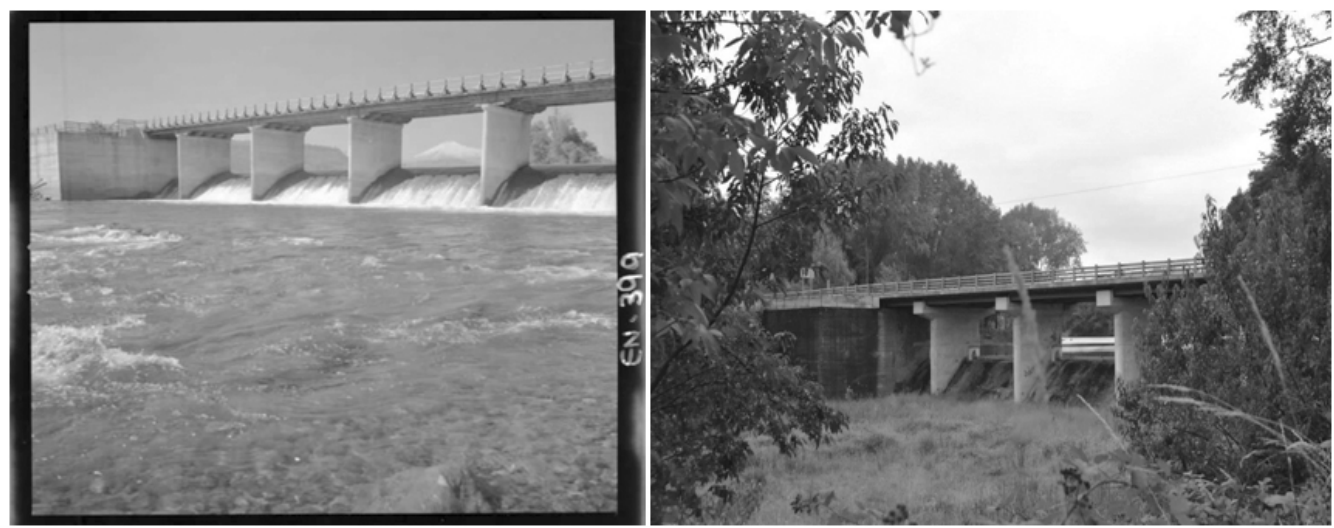

Fuente: Luis Ladrón de Guevara (1962) y fotografía registrada por autores.

La regeneración del cuerpo de agua se encuentra en el regreso de la vida al espacio. La flora y fauna que habita en el caudal ecológico del río. Es por ello que se rememoran sus usos medicinales y presencia espiritual. Constancia de ello es que, a pesar del correr de los años, las personas no han ocupado el espacio terrestre que se ha liberado por la sequía del río. Las personas son testigos del crecimiento de vegetación renoval, malesa y estiercol. El agua está, la sequía no es producto del cambio climático.El espacio está a la espera del agua que se encuentra retenida en el lago Pullinque para desviarse por el canal. El río Huenehue volverá ser como el río Huininca, tal como se contrasta en las siguientes imágenes.

\section{Figura 7}

Contraste entre río Huininca y río Huenehue en 2019
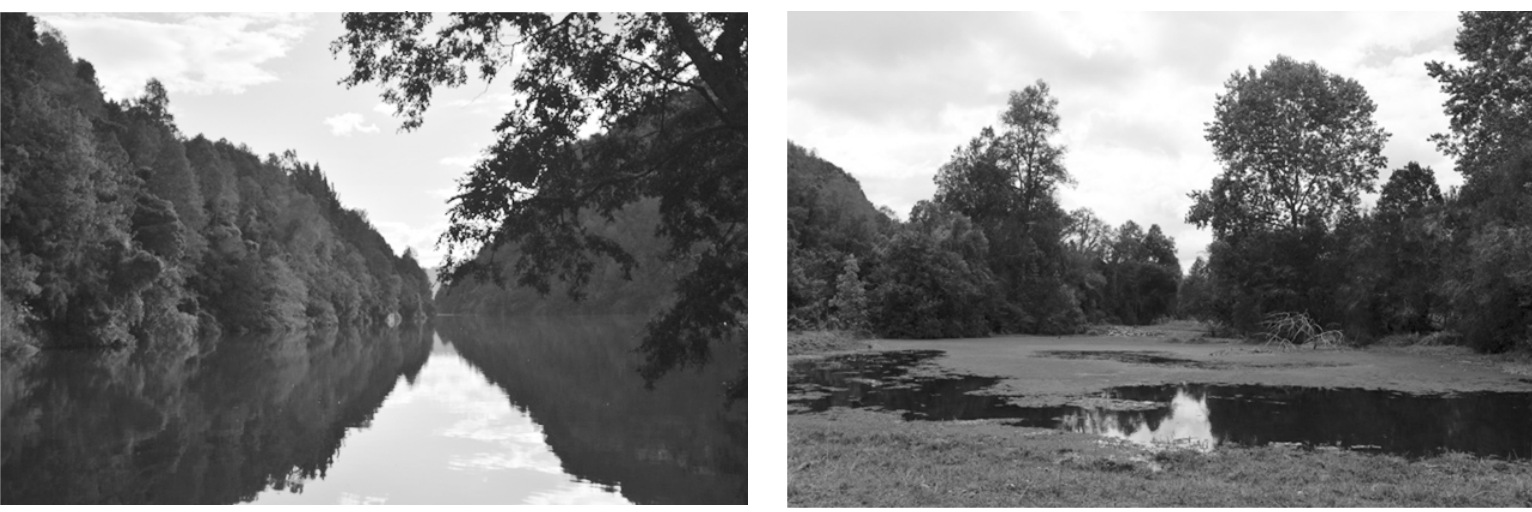

Fuente: Fotografías registradas por autores.

El estiercol que se visibiliza en el río Huenehue nace en cuerpos de agua que necesitan fluir, moverse, “correr” en lenguaje local. El reflejo del cielo en el agua del río Huininca es propio de caudales correntosos que fluyen constantemente. La regeneración del cuerpo de agua está por volver a su estado de agua en movimiento. 


\section{Proyecto de territorio y autodeterminación política}

La demanda de que el río "vuelva a correr" es compartida por los habitantes de los lof Tralcapulli y Llongahue. Se constituye como un proyecto de naturaleza (Tsing, 2011) la reconstitución del caudal ecológico.Una vez que ganen la demanda, señala uno de los interlocutores, se reforestará con vegetación nativa la ribera del río. Esto es para proteger la vida del ngen del río. La reiteración de esta solicitud tiene por objetivo retornar el caudal del agua por la importancia que esta tiene, también, con motivos rituales. En las ceremonias de machitun, las cuales son llevadas a cabo por una/un machi para curar enfermedades de personas que busquen sanación, se convocan espíritus que le comunican a la machi las causas del mal que aqueja y los remedios para curarlo. Las malas energías que se diagnostican y que se expresan necesitan expulsarse, porque o sino se quedan estancadas en ese lugar. Una de las interlocutoras explicó la relevancia local del Huenehue para estos casos:

“cuando se hacían los machitunes, ahí mismo en el río en Tralcapulli, se dejaban los males en el río para que se fueran los malos espíritus, las malas cosas. Todo eso, el río era en ese sentido... el río es lo primordial”.

Otro elemento clave de la espiritualidad es la mitología de la creación a través de la serpiente TrengTreng (que representa a la tierra o mapu) y Kay- Kay (que representa al agua o Ko) que se manifiesta muy gráficamente en el territorio que abarca Tralcapulli. En ese espacio se encuentran dos cerros que representan estos seres mitológicos fundantes de la cultura mapuche, ubicándose la población de los lof entre ambos. Según lo registrado por el cronista Diego de Rosales (1674), ambos cerros y su relación con los acuíferos dan cuenta del inicio del linaje mapuche vinculado estrechamente con los cuerpos de agua. La intervención desmedida de la Central Pullinque al perforarlo para construir un túnel en el cerro Pitrén genera un alto desequilibrio espiritual.

La dimensión territorial es un aspecto central para el mundo mapuche, desde ahí nace el fundamento de la lucha reivindicatoria por el espacio físico que permite la existencia de su cultura. A lo largo de la historia colonial, y sobre todo desde la formación del Estado de Chile, las tierras mapuche han sido jibarizadas, fragmentando al pueblo y dando paso a la usurpación por parte de la institucionalidad estatal.

Este caso analizado no es la excepción. Los Títulos de Merced en tierras ocupadas por el canal que transporta las aguas del Huenehue da cuenta de territorialidades mapuche situadas en los espacios ocupados por la hidroeléctrica. Esta controversia se refleja hasta la actualidad, acordándose en voces locales por su alto impacto geográfico y cultural. Uno de los interlocutores señala

"la instalación fue a punta de tractores, murió harta gente. A harta gente le quitaron tierra la central. Gente de Llongahue. Cuando hicieron la canal cuantos metros se ocuparon. No le pidieron permiso a nadie. Los lloncones (familias) vivían ahí y les quitaron todos esos terrenos. Les tiraban un saco de harina y la gente, como no sabían valorizar su tierra, se las vendían”.

La Central se inauguró hace 57 años y continúa siendo una problemática, en la voz de una interlocutora:

"La presencia de la central no ha significado ningún beneficio porque ni siquiera la luz nos dieron, solamente vino a puro destruir y a generar plata para ellos y para el Estado, a lucrar para el Estado. No vinieron a ayudar a las comunidades, todo lo contrario, destruyó a las comunidades. Tanto a Llongahue le inundó los terrenos, y a nosotros nos secó el río. El lago Pullinque es artificial, no es natural, donde se destruyó mucho campo, mucho terreno".

Por otro lado, la Central ha provocado fracturas sociales entre las familias mapuche de Llongahue y Tralcapulli de larga data. Actualmente, los problemas comunitarios se concentran en las divisiones internas producto de la intromisión de la empresa en las dinámicas locales. Del mismo modo que aconteció en Ralco en la década de los noventa (Moraga, 2001), la empresa incorpora personas, enganchadores, para intervenir y provocar quiebres internos que fracturan a las comunidades mapuche. Como señala un interlocutor, 
"Nosotros no pensábamos que la empresa iba a hacer esto (dividirnos) porque no teníamos idea de cómo la empresa manejaba estos temas. Ahora nos damos cuenta que en todo territorio que hay una empresa extractivista hay un quiebre interno, familiar, social fuerte y que lo genera la empresa, en todas partes. Porque ellos tienen las lucas y ellos pagan para que la gente se venda o que la gente deje de luchar. El que se vendieran algunos fue un golpe bajo de la empresa, pero bueno, teníamos que pasar por eso para también saber que la empresa hace eso, nos sirvió como aprendizaje. Uno nunca termina de conocer a sus mismos hermanos, ñañas, a sus mismas familias en realidad, porque todos los mapuche somos familia de alguna forma. Entonces eso es decepcionante, a mí al menos, ver a gente que una conoció toda una vida y que te dé la espalda y que no luche por algo que es justo”.

La estructura comunitaria se ve afectada en términos organizativos y sociales, provocando quiebres internos delimitados geográficamente entre "los del alto" y "los del bajo” para definir que los primeros accedieron a negociar con la empresa y el resto recibe las externalidades negativas. Se construyen contextos sociales convenientes para la empresa que merman a las formas organizativas locales. A pesar de ello, la demanda por el caudal ecológico vuelve a reunir a los habitantes de ambos lof. En la ruka se generan espacios de autodeterminación política y cultural (Mariman, 2012) en el entramado de decisiones comunitarias que toman por la demanda.

\section{Discusión y reflexiones}

La realización del peritaje antropológico se vuelve fructífero en cuanto a la información que proporciona. La ecología política y la antropología por demanda van más allá de la propia pericia, tal como plantean los autores:

“Ademaìs que como una prueba, el peritaje antropoloìgico es relevante para la defensa penal si se incorpora como forma de investigacioìn y conocimiento que aporta datos de los contextos socioculturales e histoìricos. Es decir, que pueden ser cruciales para la construccioìn y justificacioìn de las teoriìas del caso o porque ayudan a visualizar insospechadas lìneas o estrategias de defensa a partir de evidencia sociocultural” (Berho, Castro y Le Bonniec, 2016, p. 123).

La instalación y desarrollo de la Central Hidroeléctrica Pullinque, en su versión estatal como privada, ha provocado un profundo daño en la cotidianidad de las familias mapuche de Tralcapulli y Llongahue que habitan en la cuenca del río Huenehue. El sistema de vida se ha deteriorado sustantivamente producto de la perturbación de la geografía local, las prácticas de amedrentamiento, la división de la comunidad y, por sobre todo, la sequía del caudal ecológico del río. El deterioro del medioambiente genera un daño profundo en el ecosistema: pájaros, peces, ranas, entre otras especies de fauna nativa son de un alto valor en actividades alimenticias y productivas de las familias mapuche.

La situación de Huenehue nos permite constatar etnográficamente que la ecología política mapuche se define por las prácticas cotidianas del sentipensar los territorios en su demanda de restauración socioecológica. Son prácticas territorialmente situadas, vinculadas a micropolíticas (Rivera, 2018)lugarizadas y discursivamente asociadas a procesos globales en diversas escalas (Biersack, 2011). El sentipensar mapuche con las aguas se constata como un proceso en que se devasta la vida, se constituyen prácticas hacia la regeneración del agua como un cuerpo geográfico, cultural y espiritual. Se establece un proyecto de naturaleza, el cual se funda en dinámicas de autodeterminación política y cultural. Así se constituye el sentipensar mapuche con las aguas, como una segunda naturaleza que "es post-naturaleza, no reemplaza la naturaleza sino que, más bien, constituye la interfazentre la (primera) naturaleza, por un lado, y la cultura, el poder y la historia, por el otro" (Ibid, p. 167). El sentipensar mapuche con las aguas va en esta línea, donde se integran la historia, la cultura y el poder situados en el cuerpo de agua del Huenehue.

La desaparición de la biodiversidades una herida profunda en las comunidades mapuche que será difícil de subsanar. El Truf Truf y Kuseweke son espacios con una alta relevancia socioambiental y en la cultura mapuche local. El Truf Truf ya no regula ambientalmente la agricultura, por ejemplo, perjudicando prácticas 
agrícolas y espirituales. La ribera del río se encuentra en una geografía de la espiritualidad mapuche de alta complejidad y se ha vuelto un patrimonio cultural amenazado por el deterioro del caudal ecológico del río.Este último al encontrarse deteriorado, genera desequilibrios en la espiritualidad mapuche que se vuelven perjudiciales para la vida comunitaria de las familias mapuche. La vegetación nativa que nace en el río es de alta significancia práctica y espiritual para la medicina mapuche que se desarrolla en Tralcapulli y Llongahue: la pérdida del lawen repercute en la pérdida de la autonomía en la gestión de la salud local de las comunidades originarias. La pérdida del caudal ecológico impide el desarrollo de prácticas culturales mapuche como la huerta, agricultura a escala familiar, entre otras con una alta relevancia socioambiental.

Este texto pretende aportar a la discusión que se entabla en torno al enfoque la ecología política mapuche (Di Giminiani,2018) en la que cultura y naturaleza están imbricadas en la construcción del mundo. Es un tipo de ecología política relacionales (Escobar, 2014), cuya distinción es sentipensar en las prácticas cotidanas la autodeterminación mapuche. La investigación antropológica en estos contextos obliga a una metodología profunda y comprometida con los procesos sociales en que se sitúa la ecología política (Bustos y Prieto, 2019). Diversa literatura y la misma observación etnográfica dan cuenta de la relevancia de los procesos subjetivos en la manera de relacionarse comunitariamente y para con la naturaleza. Aquella forma de entablar lazos nace desde el territorio, desde la subalternidad de la tierra. Es por ello que los pueblos originarios, en este caso mapuche, demandan no un derecho otorgado por una institucionalidad, sino aquella relación ancestral con la tierra como un sujeto sensible y dotado de agencia.

\section{Agradecimientos}

Agradecemos a Juanita, Rosi, doña Carmen y don César (familia Huerañanco Chospe), a doña Antonia Caniucura, don Daniel Lincocheo, don David Rain, doña Carmen Rain, doña María Angélica Rain, don Francisco Huirimán y a Margarita Loncoñanco por abrirnos las puertas de sus casas e invitarnos a sentar a su mesa para conversar. A la Asociación Lewfü Wueneywue por la importante lucha que están llevando para recuperar lo justo.

María Ignacia agradece a CONICYT PFCHA/Doctorado en el extranjero Becas Chile +72180102 y al Centro de Investigaciones Interculturales e Indígenas (CIIR).

Wladimir agradece al proyecto FONDECYT Regular No 1181575 “Interculturalidad y ciudades intermedias: prácticas de movilidad y la construcción de territorialidades. El caso de La Araucanía (Chile)” y al Centro UC de Desarrollo Local (CEDEL).

\section{Notas}

\footnotetext{
${ }^{1}$ Las palabras en mapuzungun se escriben según el grafemario Azümchefe de la Corporación Nacional Indígena (2005).

${ }^{2}$ Según Ernest Moesbach, Huenehue alude al lugar en que se reunen las personas (de Moesbach, 1952). Según don David Rain, Wueneywue alude al espacio de encuentro entre las familias de Tralcapulli y Llongahue.
}

\section{Bibliografía}

Berho, M, Castro, P. y Le Bonniec, F. (2016). La pericia antropológica en la Araucanía de Chile. Revista Antropologías del Sur, 3(6), 107-126.

Barreau, A., Ibarra, J.T, Wyndham, F. y Kozak, R. (2019). Shitfs in Mapuche Food Systems in Southern Andean Forest Lanscapes: Historical Processes and Current Trends of Biocultural Homogenization. Mountain Research and development, 39(1).

Biersack, A. (2011). Reimaginar la ecología política: cultura/poder/historia/naturaleza. En: Leonardo Montenegro (ed.), Cultura y Naturaleza. Bogotá, Colombia: Jardín Botánico de Bogotá José Celestino Mutis.

Bolados, P. y Sánchez, A. (2017). Una ecología política feminista en construcción: El caso de las Mujeres de zonas de sacrificio en resistencia, Región de Valparaíso, Chile. Psicoperspectivas, 16(2), 1-13. 
Bustos, B. y Prieto, M. (2019). Ecología política en (desde y por) Chile: posibilidades, desafíos y contribuciones. En: Andrés Núñez et al. (ed.), (Las) Otras Geografías en Chile. Perspectivas sociales y enfoques críticos. Santiago, Chile: LOM Ediciones.

Cabnal, L. (2010), Feminismos diversos: el feminismo comunitario. Madrid, España: ACSUR-Las Segovias.

Canales, M. ed. (2014). Metodologías de investigación social. Introducción a los oficios. Santiago, Chile: LOM ediciones.

Catriquir, D. y Llanquinao, G. (2017). WiñonAntüZugu. Fenómeno natural, de vida y de kimün en el mapuncherakizuam. En: MapunKimün. Relaciones mapunche entre persona, tiempo y espacio. Santiago, Chile: Ocho Libros Editores.

Chihuailaf, E. (1999). Recado confidencial a los chilenos. Santiago, Chile: LOM Ediciones.

Claval, P. (1995). La géographieculturelle. París, France: Nathan.

Colectivo Situaciones (2003). Sobre el militante investigador. Recuperado de: http://eipcp.net/transversal/0406/ colectivosituaciones/es.

Corporación Nacional Indígena, (2005). Azümchefe. Hacia la escritura del mapuzugun. Temuco, Chile: Unidad de Cultura y Educación CONADI.

Curiel, O. (2009). Descolonizando el feminismo: una perspectiva desde América Latina y el Caribe. Primer Coloquio Latinoamericano sobre Praxis y PensamientoFeminista GLEFAS, Buenos Aires, Argentina.

De Moesbach, E. (1952). Voz de Arauco. Explicación de los nombres indígenas de Chile. Padre de Las Casas, Chile: Imprenta San Francisco.

Di Giminiani, P. (2018). Sentient Lands. Indigeneity, Property, and Political Imagination in Neoliberal Chile. Tucson, USA: University of Arizona Press.

Di Giminiani, P.yGonzález, M. (2018). Who Owns the Water? The relation as unfinished objectivation in the mapuche lived world. AnthropologicalForum, 28(3). 199-216.

Di Giminiani, P.(2012). Tierras ancestrales, disputas contemporáneas. Pertenencia y demandas territoriales en la sociedad mapuche rural. Santiago, Chile: Ediciones UC.

Durán, T. y Catriquir, D. (2007). Mapunüy: el nombre personal en la sociedad y cultura mapuche. Implicancias étnicas y sociales. En: T. Durán, D. Catriquil y R. Hernández (eds.), Patrimonio cultural mapuche: acercamientos metodológicos e interdisciplinarios, derechos lingüísticos, culturales y sociales. Temuco, Chile: Universidad Católica de Temuco.

ENDESA (1962). Pullinque. Santiago, Chile: Empresa Nacional de Electricidad S.A.

Escobar, A. (2016). Autonomía y diseño. La realización de lo comunal. Popayán, Colombia: Universidad del Cauca. Sello Editorial.

(2014). Sentipensar con la tierra. Nuevas lecturas sobre desarrollo, territorio y diferencia. Medellín, Colombia: Ediciones UNAULA.

(1999). El final del salvaje. Naturaleza, cultura y política en la antropología contemporánea. Bogotá, Colombia: CEREC-ICAN. 
Geertz, C. (2003). La interpretación de las culturas. Barcelona, España: Gedisa editorial.

Grebe, M. (1993). El subsistema de los ngen en la religiosidad mapuche. Revista Chilena de Antropología,12, 45-64.

Guber, R. (2013). La articulación etnográfica. Descubrimiento y trabajo de campo en la investigación de Esther Hermitte. Buenos Aires, Argentina: Biblos.

Gudynas, E. y Acosta, A. (2011). La renovación de la crítica al desarrollo y el buen vivir como alternativa. Utopía y Praxis Latinoamericana, 16, (53), 71-83.

Ingold, T. (2012). Ambientes para la vida. Conversaciones sobre humanidad, conocimiento y antropología. Montevideo, Uruguay: Ediciones Trilce.

Ladrón de Guevara, L. (1962). Bocatoma ubicada en el desagüe de la laguna Pullinque. Fotografía disponible en: http://www.bibliotecanacionaldigital.gob.cl/bnd/629/w3-article-165283.html

Leff, E. (2019). Devenir de la vida y trascendencia histórica: las vías abiertas del diálogo de saberes. Desenvolv. Meio Ambiente, 50, 4-20.

Leyva, X. y Speed, S. (2008). Hacia la investigación descolonizada: nuestra experiencia de co-labor. En Leyva, A., Burguete y Sh. Speed (Coords.),Gobernar (en) la diversidad: experiencias indígenas desde América Latina. Hacia la investigación de colaboración. Ciudad de México, México: CIESAS, FLACSO Ecuador y FLACSO Guatemala.

Lindón, A. y Hiernaux, D (Dirs.). (2006). Tratado de Geografía Humana. Barcelona, Argentina: Anthropos Editorial.

Lipietz, A. (2002). ¿Qué es la ecología política? La gran transformación del siglo XXI. Santiago, Chile: LOM Ediciones.

Marimán, J. (2012). Autodeterminación. Ideas políticas mapuche en el albor del siglo XXI. Santiago: Chile: LOM Ediciones.

Moraga, J. (2001). Aguas turbias. La central hidroeléctrica Ralco en el Alto BíoBío. Santiago, Chile: ObservatorioLatinoamericano de ConflictosAmbientales.

Nelson, M. (2013). Fifty years of hydroelectric development in Chile: A history of unlearned lessons. Water Alternatives, 6(2),195-206

Nykvist, B. (2012). Social Learning in the Anthropocene.Governance of Natural Resources in Human Dominated Systems. Doctoral thesis: Natural Resource Management. Stockholm University.

Ñanculef, J. (2016).Tayiñmapuchekimün.Epistemología mapuche - sabiduría y conocimientos. Santiago, Chile: UChile Indígena.

Quijano, A. (2000). “Colonialidad del poder, eurocen-trismo y América Latina” en Lander, Edgardo (comp.) La colonialidad del saber: eurocentrismo y ciencias sociales. Perspectivas latinoamericanas, Buenos Aires, Argentina: CLACSO.

Radding, L. y Western, J. (2010). What's in a name? Linguistics, Geography and Toponyms.Geographical Review, 100, 394-412.

Rappaport, J. (2007). Más allá de la observación participante: la etnografía colaborativa como innovación teórica. En X. Leyva (et. al.), Conocimientos y prácticas políticas reflexiones desde nuestras prácticas de conoci- 
miento situado. Ciudad de México, México: CIESAS/UNICACH/ PDTG-Perú/ISS-HIVOS.

Riquelme, W. (2019). Árboles y Geografías Sagradas de la Espiritualidad Mapuche Contemporánea.En Carballo, C. y F. Flores (comp.), Geografías de lo sagrado en la contemporaneidad.Bernal, Argentina: Universidad Nacional de Quilmes.

Rivera, S. (2018). Un mundo ch'ixi es posible. Ensayos desde un presente en crisis. Buenos Aires, Argentina: Tinta Limón.

Rosales, D. ed. (1674). Historia General del Reino de Chile. Flandes indiano. Valparaíso, Chile: Imprenta del Mercurio.

Rozzi, R. y Schu?ttler, E. (2015). Primera década de investigación y educación en la Reserva de la Biosfera Cabo de Hornos: el enfoque biocultural del Parque EtnobotánicoOmora. Anales Instituto Patagonia, 43(2), 1943.

Said, E. (2010). Orientalismo. Barcelona, España: Mondadori.

Segato, R. (2013). La crítica de la colonialidad en ocho ensayos y una antropología por demanda. Buenos Aires, Argentina: Prometeo libros.

Skewes, J.C., Guerra, D., Rojas, P. y Mellado, M. (2011). ¿La memoria de los paisajes o los paisajes de la memoria? Los enigmas de la sustentabilidad socioambiental en las geografías en disputa. Desenvolvimento e Meio Ambiente, 23, 39-57.

Spivak, G. (2011). ¿Puede hablar el subalterno? Buenos Aires, Argentina: El cuenco de plata.

Toledo, V. (2019). What are we saying when we talk about Sustainability? An ecological political proposal.Sustainable Human Development. EO21.

Tsing, A. (2011). La naturaleza en construcción. En: Leonardo Montenegro (ed.), Cultura y Naturaleza. Bogotá, Colombia: Jardín Botánico de Bogotá José Celestino Mutis.

Ulloa, A. (2016). Feminismos territoriales, en América Latina: defensas de la vida frente a los extractivismos. NÓMADAS, 45, 123-139.

Yáñez, N. y Molina, R. (2011). Las aguas indígenas en Chile. Santiago, Chile: LOM Ediciones.

\section{Testimonios orales}

Antonia Caniucura, Pillankuche de Lof Llongahue. Conversación registrada en enero 2019

Carmen Aída Chospe, Lof Tralcapulli. Conversación registrada en febrero de 2019.

César Huereñanco, Lof Tralcapulli. Conversación registrada en febrero de 2019.

Juanita Huereñanco, Lof Tralcapulli. Conversación registrada en febrero de 2019.

Daniel Lincocheo, Presidente Asociación Lewfü Wueneywue. Conversación registrada en febrero de 2019.

David Rain, Nguillatufe de Lof Tralcapulli. Conversación registrada en enero de 2019.

Francisco Huiriman, Lof Tralcapulli. Conversación registrada en febrero de 2019. 
María Angélica Rain, Lof Tralcapulli. Conversación registrada en febrero de 2019.

Margarita Loncoñanco, Lawentuchefe de Lof Llongahue. Conversación registrada en enero de 2019. 